\title{
Encapsulated functionalized stereocomplex PLA particles: an effective system to support enzymes for mucus degradation
}

Stefania Boi ${ }^{l}$, Elena Dellacasa ${ }^{1}$, Paolo Bianchini ${ }^{2}$, Paola Petrini ${ }^{3}$, Laura Pastorino $^{1 \S}$, Orietta Monticelli $^{4 *}$

${ }^{1}$ Department of Informatics, Bioengineering, Robotics and Systems Engineering, University of Genoa, Via all’ Opera Pia 13, 16145 Genoa, Italy.

${ }^{2}$ Nanoscopy and NIC, Istituto Italiano di Tecnologia, Via Morego 30 16163, Genoa, Italy.

${ }^{3}$ Department of Chemistry, Materials and Chemical Engineering 'G. Natta', UdR INSTM Milano Politecnico, Politecnico di Milano, Piazza Leonardo da Vinci 32, 20133 Milan, Italy.

${ }^{4}$ Department of Chemistry and Industrial Chemistry, University of Genoa, Via Dodecaneso 31, 16146, Genoa, Italy.

Keywords: PLA; aminolized particles; papain; alginate lyase; engineered polymeric microcapsules. 
Abstract. In this work, the preparation of a novel enzyme carrier based on a polymer multicomponent system was assessed. Indeed, the design of the above system considered several issues that are the need of applying a biodegradable polymer carrier, characterized by a nanometric dimension, thus suitable to diffuse into the dense mucus structure, with functionalities capable of interacting/reacting with enzymes but resistant to enzymatic degradation. The particles were prepared from solutions containing equimolar amount of highmolecular-weight poly(L-lactide) (PLLA) and poly(D-lactide) (PDLA) and by applying the nanoprecipitation method. Dynamic Light Scattering (DLS) measurements allowed to establish the optimal preparation conditions to obtain polymer particles characterized by diameters lower than $1 \mu \mathrm{m}$, which dimensions were confirmed by Field Emission Scanning Electron Microscope (FE-SEM) analysis. In order to produce surface functionalization, necessary for anchoring enzymes, the stereocomplexed particles, whose structuration was confirmed by Differential Scanning Calorimetry (DSC) measurements, underwent an amminolysis reaction by using a diamine as reactant. The treated particles were characterized by means of FE-SEM, Fourier-Transform Infrared Spectroscopy (FTIR), DLS and zeta potential measurements and their characteristics were compared with those of the neat PLLA/PDLA particles. The degree of functionalization turned out to depend on the applied conditions, it increasing by enhancing the reaction time. The activity of enzymes, i.e. papain and alginate lyase, anchored to the particles -, was evaluated by Quartz Crystal Microbalance (QCM) and UV measurements. Moreover, with the aim at exploiting the material for an inhalation administration, a method to encapsulate the enzyme-- particles systems was assessed. Conversely to free enzymes, the developed systems were found to be capable of diminishing the viscosity of two hydrogels, $a d$ hoc prepared and based on the main constituents of the real mucus.

\section{Introduction}


The study of enzyme immobilization, which has been mainly concentrated in finding new types of carriers and technologies, has been investigated with a continuous level of interest. ${ }^{1}$ Several inorganic supports were used for the immobilization of enzymes, such as gold, ${ }^{5}$ silica, ${ }^{6}$ magnetic nanoparticles, ${ }^{7,8}$ and mesoporous silicas. ${ }^{9}$ Anyway, when the above materials are used in biomedical applications, important issues have to be taken into account, such as the interactions between the enzyme and the inorganic supports as well as their bio-absorption capacity. On this respect, polymers, which are characterized by a relevant versatility and a good biocompatibility and biodegradability can overcome these drawbacks. Indeed, several natural polymer materials like cellulose ${ }^{10}$, alginate,${ }^{11}$ chitosan, ${ }^{12}$ chitin, ${ }^{13}$ starch,${ }^{14}$ sepharose,${ }^{15}$ pectin, ${ }^{16}$ were applied as support materials. Nevertheless, the study of the application of synthetic polymers is not well documented as that dealing with the exploitation of natural polymers, although the former materials hold characteristics which can be considered ideal for an enzyme carrier, that are good mechanical stability and easy modification. As far as the latter feature is concerned, it is worth underling that generally in order to enhance the operational stability in solid supports, thus increasing the immobilizing efficiency, covalent attachments to activated supports were used for enzyme immobilization. ${ }^{17}$ In this light, the functionalization and the facile modification of the carrier represent key properties for the development of the supported enzyme system.

Summarizing, the designing of a polymer/enzyme system to be used in biomedical applications, which is the object of the present work, is based on the consideration of several issues, that are: i) the features of the polymer, mainly in terms of its degradability, ii) the types of interactions/linkages which can occur between the enzyme and the support, iii) the vehiculation of the particles and iv) the specific activity of the supported enzyme. All the above aspects were taken into account in our study, having in mind a system which might find applications for the treatment of different pathologies, such as cystic fibrosis (CF). 
As polymer matrix, polylactic acid (PLA) was exploited, being a biocompatible synthetic polymer widely used as drug support and in various other biomedical applications. ${ }^{18,19}$ In particular, stereocomplex PLA (sc-PLA), which is produced by the combination of the enantiomeric PLLA and PDLA, was taken into account because of the higher thermal and hydrolysis resistance with respect to either mere PLLA or PDLA. ${ }^{20,21}$ On this respect, it is worth underling that, for the envisaged applications, the polymer matrix should be biodegradable but not easily decomposed by the carried enzymes. However, the application of PLA-based particles/nanoparticles in protein delivery generally is characterized by low entrapment efficiencies, burst release, instability of encapsulated hydrophilic protein and partial protein release. $^{22}$

Taking into account the above issues, we designed a novel polymer/enzyme system, whose novelty lies in the method adopted to prepare functionalized particles - suitable to covalently attach enzymes. An equimolar mixture of PLLA/PDLA was used as polymer matrix to obtain sc-PLA particles by applying a simple precipitation approach. The subsequent functionalization procedure, based on an aminolysis reaction, is potentially capable of promoting the formation of amino groups on the polymer surface, when using a diamine, as well as of tuning the particles dimension. ${ }^{23-26}$ Indeed, it is reported that due to the intrinsic mechanism of aminolysis reaction, erosion of the polymer inevitably takes place, thus reducing the dimensions of the polymer substrate. The functionalized particles were covalently coupled to papain and alginate lyase. The so modified particles were characterized in terms of efficiency of enzyme immobilization and of residual catalytic activity. In order to render the prepared system applicable to an inhalation administration, the prepared sc-PLA particles were encapsulated (Scheme 1). ${ }^{27}$ Nanostructured polyelectrolyte microcapsules were selected as ideal microcarriers, due to their versatility and wide applicability. ${ }^{28-30}$ The microcapsules were fabricated through the electrostatic Layer-by-Layer (LbL) self-assembly of a multilayered shell 
onto a sacrificial micro-core. ${ }^{31-33}$ Specifically, it has been demonstrated that biomacromolecules can be co-precipitated in calcium carbonate $\left(\mathrm{CaCO}_{3}\right)$ microparticles in the process of growth from the mixture of aqueous solutions of calcium chloride $\left(\mathrm{CaCl}_{2}\right)$ and sodium carbonate $\left(\mathrm{Na}_{2} \mathrm{CO}_{3}\right) .{ }^{34}$ In this work, poly-L-arginine hydrochloride and dextran sulfate sodium salt were used, as polycation and polyanion respectively, for the formation of the multilayered shell onto $\mathrm{CaCO}_{3}$ sacrificial microcores, co-precipitated with the particles.$-{ }^{35,36}$ The obtained particles --loaded $\mathrm{CaCO}_{3}$ microparticles were characterized by FE-SEM and FTIR in order to prove the actual particles - incorporation. Moreover, free papain was also coprecipitated in $\mathrm{CaCO}_{3}$ with the aim at promoting the self-degradation of the hollow microcapsules, obtained after the sacrificial template removal. The shell degradation process was monitored by confocal microscopy measurements. Finally, the degradation of two ad hoc prepared hydrogels by the developed systems was studied by viscosity measurements.

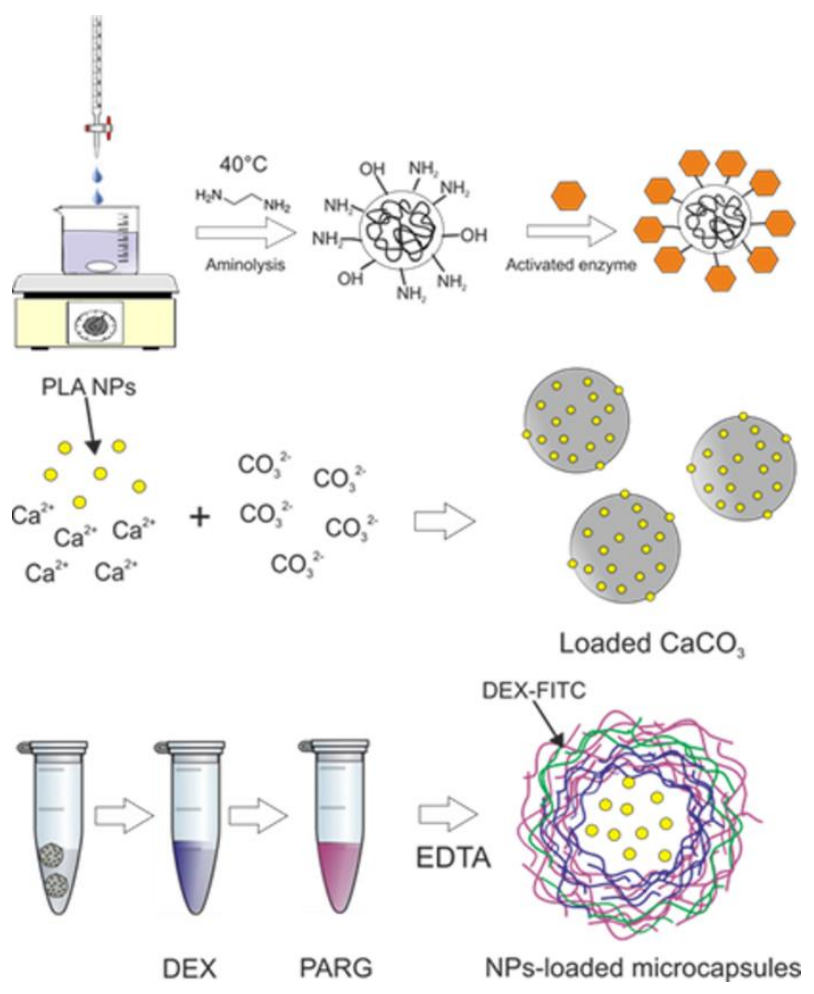

Scheme 1. Scheme of the enzyme-- particles systems preparation and encapsulation.

\section{Experimental}




\subsection{Polymer particles preparation}

Polymer particles were prepared by using solutions characterized by different polymer concentrations (from 0.5 to $2 \% \mathrm{w} / \mathrm{v}$ ) and by solubilizing equimolar quantity of PLLA (1010 Synterra, average molecular weight $\left.1 \cdot 10^{5}\right)$ and PDLA (1010 Synterra, average molecular weight $1 \cdot 10^{5}$ ) in dichloromethane (DCM, Sigma-Aldrich) and dimethylformamide (DMF, Sigma-Aldrich). In the following the optimized conditions are reported: the mixture based on DCM was added dropwise and under constant stirring into isopropanol (iPrOH, SigmaAldrich), using a volume ratio DCM/iPrOH of 1:2. The mixture was left for 5 hours in an open reactor in order to allow DCM evaporation. The obtained particles were stored at $4^{\circ} \mathrm{C}$.

\subsection{Polymer particle functionalization}

$10 \mathrm{~mL}$ of the particles - dispersion in $\mathrm{PrOH}$ were put in a reactor under argon atmosphere and then $10 \mathrm{~mL}$ of a $10 \% \mathrm{v} / \mathrm{v}$ solution of ethylenediamine (Sigma-Aldrich) in $\mathrm{PrOH}$ were added. The reaction was stopped after 30 and 60 minutes. The particles - were washed three times with Milli-Q water and stored at $4^{\circ} \mathrm{C}$. The particles - treated for 60 min were applied in the further experiments.

\subsection{Enzyme immobilization}

The enzymes papain from Carica papaia (code P76218) and alginate lyase (code A1603), were covalently coupled to the functionalized PLA via the $\mathrm{N}$-(3-dimethylaminopropyl)- $\mathrm{N}^{\prime}-$ ethylcarbodiimide (EDC)/N-hydroxysuccinimide (NHS) coupling reaction. ${ }^{37}$ In brief, a Phosphate Buffered Saline (PBS) solution containing $1 \mathrm{mg} / \mathrm{mL}$ of EDC, $0.8 \mathrm{mg} / \mathrm{mL} \mathrm{NHS}$ and $1 \mathrm{mg} / \mathrm{mL}$ of enzyme was prepared and left under constant shaking for 2 hours at room temperature. Then $1 \mathrm{~mL}$ of particles - was centrifuged, the supernatant was removed and replaced with $1 \mathrm{~mL}$ of enzyme activated solution and left under shaking overnight. The enzyme-conjugated PLA particles - were then centrifuged and washed three times with pure 
water. Supernatants from every washing step were retained for the determination of the conjugated enzyme amount. The obtained enzyme-particles -- were stored in water at $4{ }^{\circ} \mathrm{C}$ until their use. All reagents used for enzymes immobilization were from Sigma-Aldrich.

\subsection{Micro-encapsulation of PLA particles}

$\mathrm{CaCO}_{3}$ sacrificial templates were fabricated, according to Volodkin et al., immediately before microcapsules preparation. ${ }^{38}$ The enzyme-particles were incorporated into the $\mathrm{CaCO}_{3}$ microparticles by co-precipitation. ${ }^{34}$ Briefly, $\mathrm{CaCO}_{3}$ loaded templates were synthesized by mixing $0.5 \mathrm{~mL}$ of enzyme-- particles dispersion with $0.5 \mathrm{~mL}$ of $0.66 \mathrm{M} \mathrm{CaCl}_{2}$. The free papain co-precipitated $\mathrm{CaCO}_{3}$ microparticles were prepared by dissolving papain in the enzymeparticles dispersion at a concentration of $4 \mathrm{mg} / \mathrm{mL}$. At this point, $1 \mathrm{~mL}$ of $0.33 \mathrm{M} \mathrm{Na}_{2} \mathrm{CO}_{3}$ was added to the as above described solution $\left(\mathrm{CaCl}_{2}\right.$, enzyme-particles and free papain) under vigorous stirring ( $\approx 900 \mathrm{rpm})$. After $20 \mathrm{~s}$, stirring was stopped. This resulted in the precipitation of vaterite, $\mathrm{a} \mathrm{CaCO}_{3}$ metastable porous polymorph having spherical shape. ${ }^{39}$ The supernatant was removed by centrifugation and the microparticles were washed three times with ultrapure water to remove residual salts and unincorporated particles- and free papain. Supernatants from every washing step were retained for determination of the entrapped enzymes, according to the procedure previously described. Finally, microcapsules were prepared using the LbL technique. ${ }^{31}$ Briefly, $\mathrm{CaCO}_{3}$ cores were alternately immersed in dextran sulfate sodium salt (dextran from now on) from Leuconostoc spp (DEX, Mw 9,000-20,000) and poly-L-arginine hydrochloride (PARG, Mw 5,000-15,000) (polyarginine from now on) solutions at $0.5 \mathrm{mg} / \mathrm{mL}$ in $0.15 \mathrm{M}$ sodium chloride $(\mathrm{NaCl})$ for 15 minutes under mild agitation. Every deposition step was followed by three centrifugation/washing steps and supernatants were every time replaced with pure water. The procedure was repeated until three bilayers of DEX/PARG were reached. For visualization, the shell of the microcapsules was labeled by depositing as fifth layer Dextran- FITC (DEX-FITC, $\mathrm{Mw}=70 \mathrm{kDa}$ ) at a concentration of $0.5 \mathrm{mg} / \mathrm{mL}$ in $0.15 \mathrm{M} \mathrm{NaCl}$. 
$\mathrm{CaCO}_{3}$ was then dissolved by immersing the coated microparticles in $0.2 \mathrm{M}$ ethylenediaminetetraacetic acid disodium salt (EDTA) at pH 7 for $30 \mathrm{~min}$, followed by three washings in pure water. All used reagents were from Sigma-Aldrich.

\subsection{Characterization}

A Zeiss Supra 40 VP FE-SEM equipped with a backscattered electron detector was used to examine the particle morphologies. All samples were thinly sputter-coated with carbon using a Polaron E5100 sputter coater.

FTIR spectra were recorded on a Bruker IFS66 spectrometer in the spectral range 400-4000 $\mathrm{cm}^{-1}$.

DSC analysis was performed under a continuous nitrogen purge on a Mettler calorimetric apparatus, model DSC1 STAR ${ }^{\mathrm{e}}$ System. Both calibrations of heat flow and temperature were based on a run in which one standard sample (indium) was heated through its melting point. The samples, having a mass between 2.5 and $6 \mathrm{mg}$, were heated from room temperature to 200 ${ }^{\circ} \mathrm{C}$, then cooled down to room temperature and finally heated to $200{ }^{\circ} \mathrm{C}$ again. A scanning rate of $10^{\circ} \mathrm{C} / \mathrm{min}$ was used both on heating and cooling.

The size distributions of the particles- and their surface were measured by DLS and Zeta Potential with a Zetasizer Nano ZS (Malvern Instruments, Worcestershire, U.K).

Confocal microscopy was a Leica TCS SP5 STED-cw (Leica Microsystems CMS, Mannheim, Germany) inverted confocal laser scanning microscope equipped with a supercontinuum laser, up to 8 simultaneous laser lines can be chosen in the spectral window 470-670nm. We used a Leica 63xPL APO1.4 NA oil immersion objective (Leica Microsystems CMS, Mannheim, Germany). Images were obtained exciting a the $488 \mathrm{~nm}$ and collecting in spectral window 500$550 \mathrm{~nm}$, pinhole was 1 airy unit, line speed $1 \mathrm{KHz}$, line averages 48 .

The degradative ability of the free and conjugated enzymes, towards mucin in the case of papain and towards alginate in the case of alginate lyase, was evaluated in situ and in real time 
using a quartz crystal microbalance, with dissipation monitoring (QCM-D, KSV Z500). QCMD technique has been already described in detail. ${ }^{40,41}$ Briefly, QCM-D measures simultaneously the change in frequency and in energy dissipation of an oscillating quartz crystal in response to the adsorption/desorption of material to/from its surface. For viscoelastic layers, such as protein or polysaccharidic ones, the QCM-D response is modelled using a Voigt model to estimate the deposited or detached mass. ${ }^{42,43}$ Quartz crystals with a diameter of 1.5 $\mathrm{cm}$, a fundamental frequency of $5 \mathrm{MHz}$ and gold electrodes were used in this work. Frequency changes at the $3 \mathrm{rd}, 5$ th, 7 th and 9 th overtones were followed as a function of time. A Teflon liquid chamber with a volume of $2 \mathrm{~mL}$ was used. The experiments were carried out as follows. As a first step, the measuring chamber was filled with pure water for the papain degradation experiment and with potassium phosphate buffer $(0.1 \mathrm{M}$ at $\mathrm{pH} 6.3)$ for the alginate lyase one. The frequency of the crystal suddenly decreased and it was allowed to stabilize for 5 minutes. Then, mucin $(0.5 \mathrm{mg} / \mathrm{mL})$ or alginate $(1 \mathrm{mg} / \mathrm{mL})$ were introduced in the measuring chamber and allowed to adsorb to the surface of the crystal until frequency stabilization (30 minutes). The mucin or alginate adsorption was followed by three 10 minutes rinsing steps in order to remove the unadsorbed molecules. The free enzyme solutions $(0.1 \mathrm{mg} / \mathrm{mL})$ or the corresponding amount of conjugated enzyme-- particles were then injected into the chamber and let to interact with the previous layer for 30 minutes. Three 10 minutes rinsing steps were finally performed. The data analysis was performed using the QCM Impedance Analysis software (KSV Instruments, version 3.11). All used reagents were from Sigma-Aldrich.

The viscosity of the hydrogels and of that of the treated samples with the prepared enzymebased systems was analysed at $37^{\circ} \mathrm{C}$ by using a viscosimeter Brookfield mod. DV-II+.

\section{Results and discussion}




\subsection{Particle preparation and characterization}

The research has been preliminary focused on the preparation of polymer particles starting from solutions containing equimolar quantity of PLLA and PDLA, by exploiting the simple nanoprecipitation procedure, which consists in the precipitation of particles- when the polymer solution is added to the non-solvent. ${ }^{44}$ As mentioned in the Experimental Section, different polymer concentration and two types of solvents, namely DMF and DCM, were used. The choice of the solvent, used in the precipitation approach, should take into account its dielectric constant, which has to be dissimilar from that of the non-solvent. ${ }^{44,45}$ Although in the case of DMF and $\mathrm{iPrOH}$ the difference of the above parameter is higher than that related to the pair $\mathrm{DCM} / \mathrm{iPrOH}$, it is worth underling that the procedure, which has to be adopted, is more complicated that the one used for the particles prepared starting from DCM. In the case of the exploitation of DMF, in order to promote the polymer solubilization it is necessary to heat the mixture (at ca. $80^{\circ} \mathrm{C}$ ) as well as remove the solvent before carrying out the aminolysis reaction, which is performed in $\mathrm{iPrOH}$. With the aim at avoiding the particles - heating at high temperature, DMF removal was accomplished by several steps of washing, consisting in the particles - centrifugation, in the removal of the dispersing medium and in the subsequent addition of iPrOH. Despite the repeated washings, as proved by FTIR analysis (Figure S1), this treatment is not capable of complete removing DMF, which remains absorbed into the polymer matrix. Taking into account these considerations, although the use of DMF allows to obtain particles - characterized by lower dimension than those prepared by exploiting DCM (Table S1), the latter solvent was used, studying the influence of polymer concentration on the particles - features. In Table 1, DLS results are summarized, comparing the characteristics of the particles- prepared starting from three polymer concentrations, namely 2,1 and $0.5 \% \mathrm{w} / \mathrm{v}$. 
Table 1. Characteristics of the prepared PLLA/PDLA particles -.

\begin{tabular}{lllc}
\hline Sample code & Polymer concentration & Average diameter & PDI \\
& {$[\mathrm{m} / \mathrm{v} \%]$} & {$[\mathrm{nm}]$} & \\
\hline PLLA/PDLA_DCM_0.5_0 & 0.5 & 779 & 0.402 \\
PLLA/PDLA_DCM_1_0 & 1 & 1350 & 0.642 \\
PLLA/PDLA_DCM_2_0 & 2 & 1743 & 0.144
\end{tabular}

As reported in the literature for other polymer matrices, ${ }^{46,47}$ it is clear evident that by increasing the polymer concentration, the average diameter increases. In order to further elucidate the morphology of the prepared system, FE-SEM measurements were carried out by investigating the particles - which resulted to be characterized by the smallest dimension, namely those prepared by using a polymer concentration of $0.5 \% \mathrm{w} / \mathrm{v}$. The micrograph reported in Figure 1 shows that the particles -, which hold a diameter of ca. $100 \mathrm{~nm}$, result to be aggregate in cluster with an average dimension of ca. $700 \mathrm{~nm}$ in agreement with the DLS results. Although, for other polymer particles -, different kinds of stabilizers were used to facilitate their dispersion, such as dextran, poloxamer and polysorbat, ${ }^{45}$ in our system the exploitation of such molecules was avoided, considering the final application in the biomedical field. Furthermore, as it will be reported in the following paragraph, the - surface functionalization turns out to help the particles - disaggregation. 


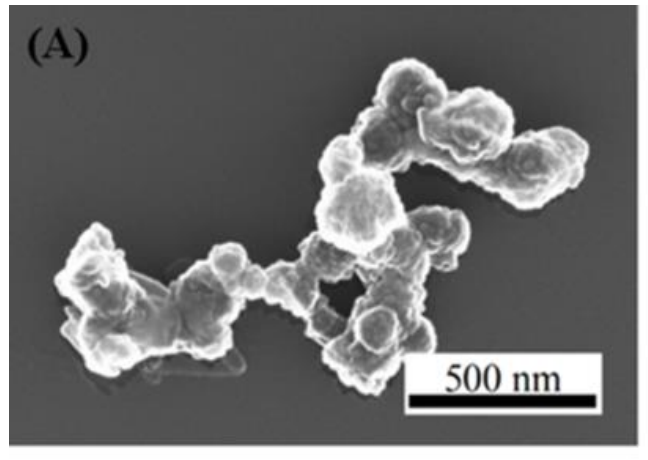

(B)
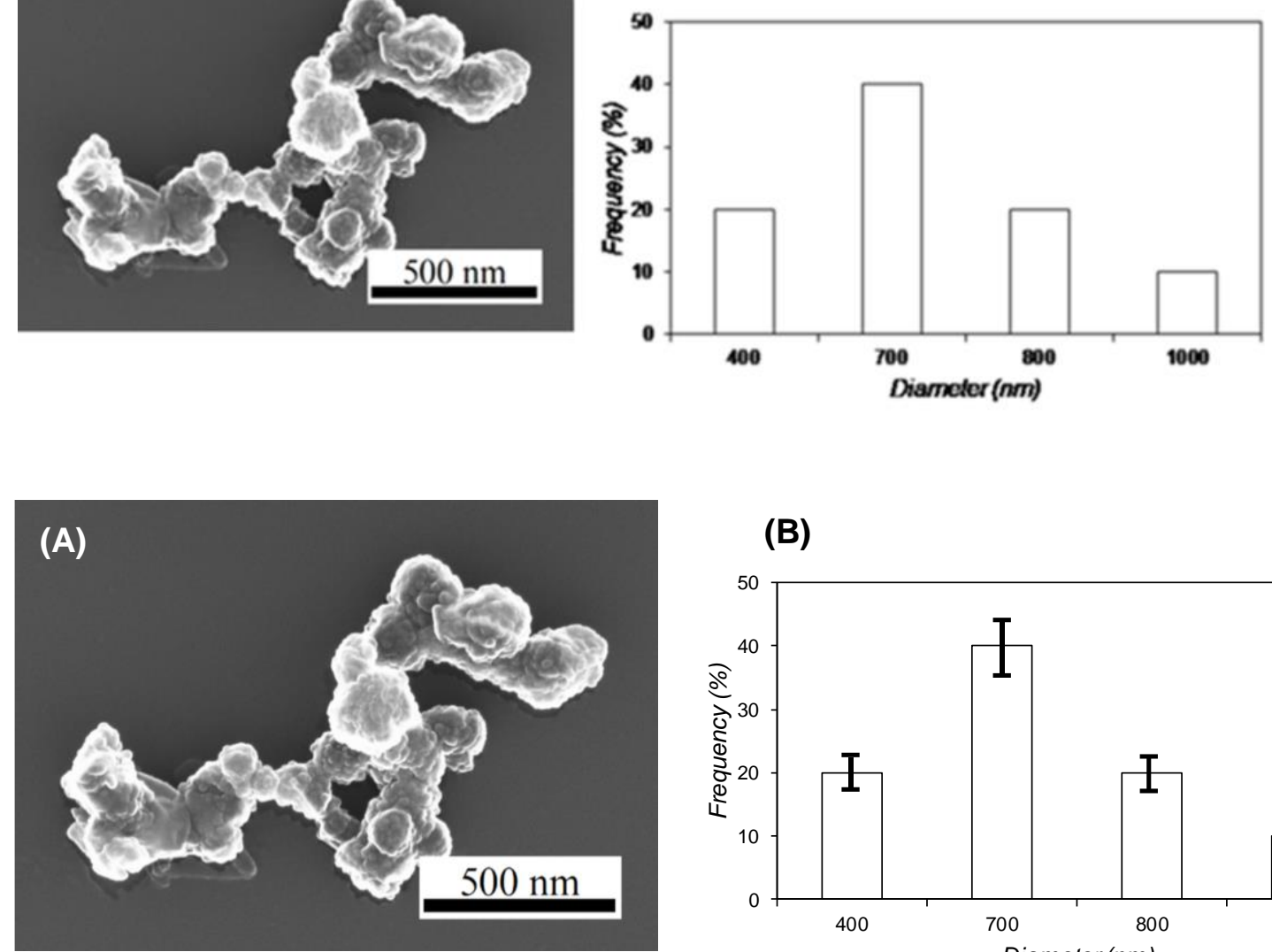

(B)

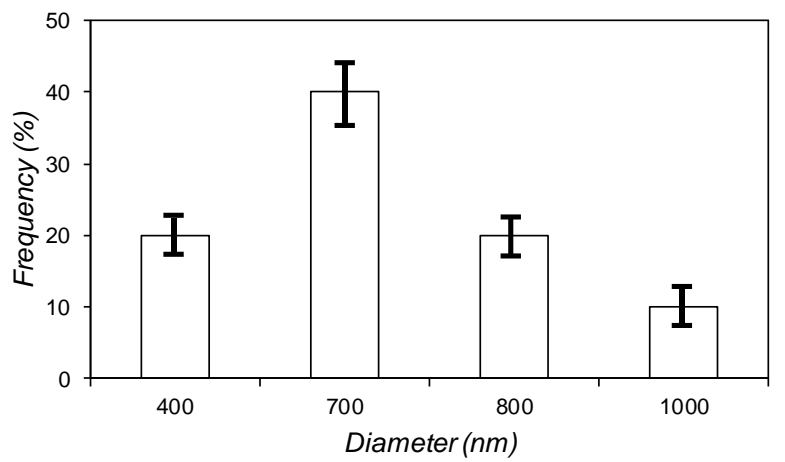

Figure 1. (A) FE-SEM micrograph of the sample PLLA/PDLA_DCM_0.5_0 and (B)

histogram of polymer particles - cluster distribution (sample PLLA/PDLA_DCM_0.5_0).

The thermal properties of the prepared particles - were studied by means of DSC (Figure 2).

The thermogram of the sample PLLA/PDLA_DCM_0.5_0 exhibits only an endotherm of fusion at about $200{ }^{\circ} \mathrm{C}$, ascribable to the melting of stereocomplex crystallites. ${ }^{20}$ 


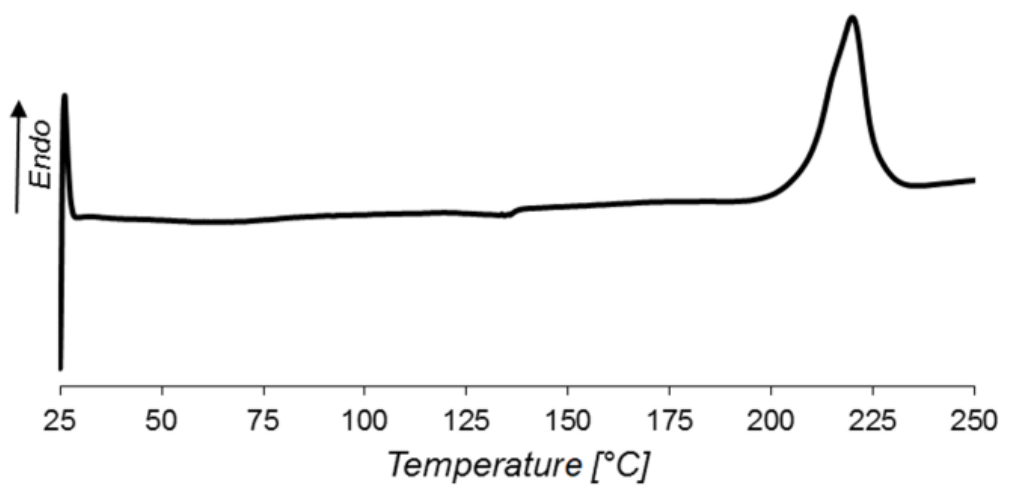

Figure 2. DSC trace of the sample PLLA/PDLA_DCM_0.5_0.

The obtained results are noteworthy as they demonstrate that the adopted procedure allows the complete system sterecomplexation, which implies the formation of a substrate characterized by enhanced properties, particularly in terms of degradation resistance, with respect to the two enantiomeric pair. Moreover, as no cold crystallization events can be detected upon heating, it is possible to infer that the slow particles - formation promotes also the polymer structuring. Indeed, the high system crystallinity (ca. 50\%, calculated by using ideal enthalpies of fusion of $142 \mathrm{~J} / \mathrm{g}$ for stereocomplex crystals ${ }^{20}$ ) may contribute to the stability of the polymer matrix, as it is well documented that the enzymatic degradation decreases by increasing the polymer crystallinity. ${ }^{47}$

\subsection{Particles functionalization}

The particles - functionalization was accomplished by using an aminolysis reaction. ${ }^{23-25}$ As described in the Experimental section, some of the reaction parameters, such as the temperature, the diamine concentration and the ratio particles -/reagent, were kept constant, while it was studied the influence of the reaction time on the particles - features. Moreover, only the particles - prepared by using a polymer concentration of $0.5 \% \mathrm{w} / \mathrm{v}$, namely those 
characterized by the smaller diameter, were exploited for the functionalization. In Table 2, the characteristics of the particles - in terms of average diameter and zeta potential $(\zeta)$ are given.

Table 2. Characteristics of the neat PLLA/PDLA and of the treated particles -.

\begin{tabular}{llllc}
\hline Sample code & Reaction time & Average diameter & PDI & $\zeta$ \\
& {$[\mathbf{m i n}]$} & {$[\mathrm{nm}]$} & & {$[\mathbf{m} \boldsymbol{V}]$} \\
\hline PLLA/PDLA_DCM_0.5_0 & 0 & 779 & 0.402 & -26.1 \\
PLLA/PDLA_DCM_0.5_30 & 30 & 360 & 0.178 & -14.9 \\
PLLA/PDLA_DCM_0.5_60 & 60 & 375 & 0.289 & -7.3
\end{tabular}

Considering the latter parameter, the neat polymer particles - show a negative $\zeta$, because of the presence of terminal carboxylic groups of PLA, which value is in agreement with those reported in the literature. ${ }^{47}$ The treatment of the particles - with the diamine leads to a decrease of $\zeta$. The above decrement turned out to depend on the reaction time, the $\zeta$ being $-14,9$ for the particles - treated for $30 \mathrm{~min}$ and -7.3 for those which underwent a 60 minutes reaction. It is relevant to underline that the decrease of $\zeta$ might be related to the formation of amino groups on the surface, whose concentrations seems to be connected with the reaction time. Although the decrement of the $\zeta$, it is worth underlining that the residual negative charge of the particles surface represents an advantage for their mobility in mucus. Indeed, Crater et al. ${ }^{48}$ reported about faster diffusing times of anionic compared to cationic particles. Furthermore, also the particle dimensions turned out to be affected by the treatment, as the average diameters of both the treated samples were almost halved. The FE-SEM micrographs, reported in Figure 3A seems to confirm the DLS analysis. In the treated samples, the particles - are more detached and characterized by a different surface morphology with respect to the neat ones. Conversely 
to the latter particles -, which are characterized by a relevant roughness, the surface of those which underwent the aminolysis reaction, shows a smoother structure.
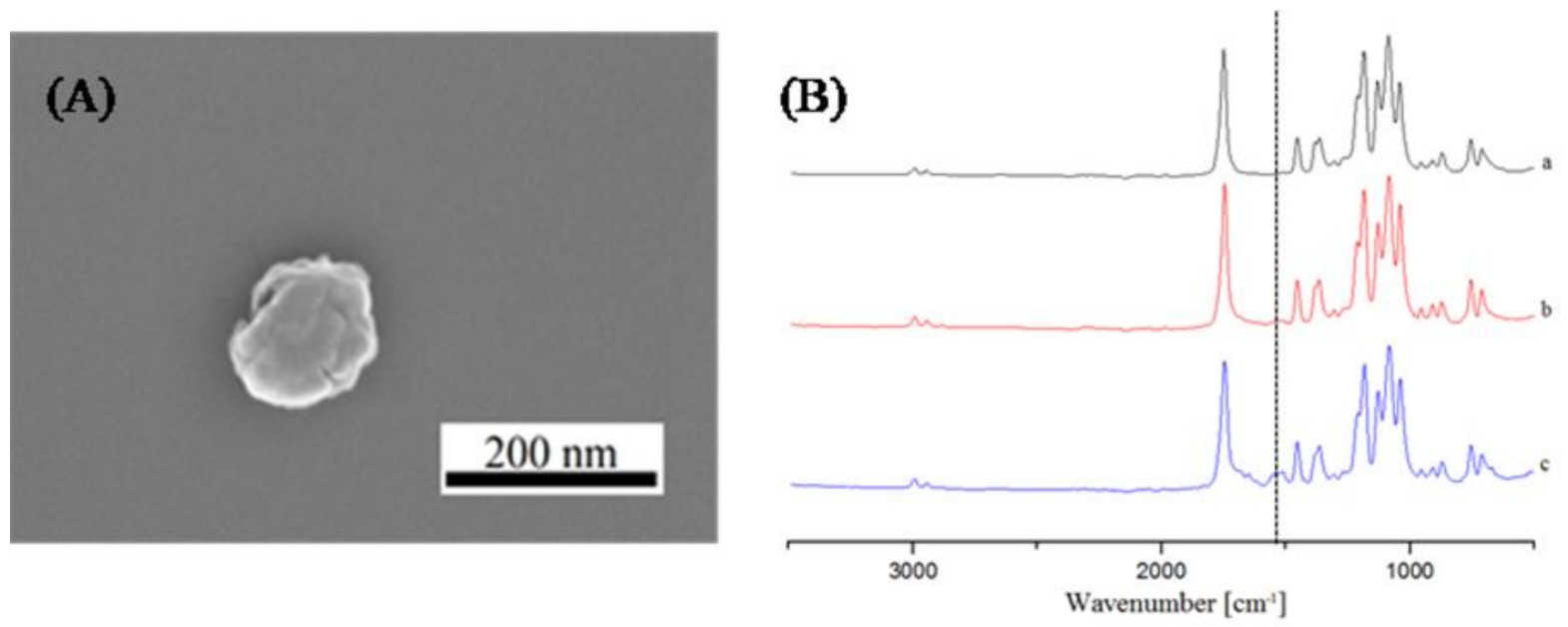

Figure 3. (A) FE-SEM micrograph of PLLA/PDLA_DCM_0.5_60; (B) FTIR spectra of: (a) PLLA/PDLA_DCM_0.5_0,

and

PLLA/PDLA_DCM_0.5_60.

This peculiar behavior might be ascribed to the erosion effect of the aminolysis, which reaction results in cleavage of ester bonds and simultaneous generation of amine groups, when it is used a diamine. ${ }^{23-25}$ Moreover, the formation of the latter groups on the surface of the particles could be responsible for the repulsion of the particles -, which effect might promote their disaggregation.

In order to support the results, FTIR characterization was performed. Figure $3 \mathrm{~B}$ compares the FTIR spectra of the neat PLLA/PDLA particles - (PLLA/PDLA_DCM_0.5_0) with those of the treated ones (PLLA/PDLA_DCM_0.5_30 and PLLA/PDLA_DCM_0.5_60). For the former sample, strong bands were observed, such as the carbonyl stretching mode near 1760 $\mathrm{cm}^{-1}$, and bands at 2900 and $1200 \mathrm{~cm}^{-1}$ corresponding to $\mathrm{CH}_{2}$ and $\mathrm{C}-\mathrm{C}$ stretching, respectively. In the treated particles, together with the characteristic bands, which are present in the spectrum of PLA, ${ }^{49}$ a new band at ca. $1600 \mathrm{~cm}^{-1}$ appears which can be assigned to amide group. 
Moreover, it is worth underling that the intensity of this signal increases by increasing the reaction time. These results, together with the previous described findings, demonstrate the occurrence of the aminolysis reaction and the possibility to modulate the features of the particles, particularly in terms of the functionalization degree by changing the reaction conditions.

\subsection{Characterization of enzyme particles -- systems}

With the aim at applying our designed systems in pathologies characterized by the overproduction of a high viscous mucus, two types of enzymes, with a specific activity over the mucus components, namely papain and alginate lyase, were put in contact with the particles . Indeed, papain, which is a proteolytic enzyme (EC 3.4.22.2) was demonstrated to have antibacterial, anti-inflammatory and mucolytic properties, so that its use was proposed for overcoming the mucus barrier in oral and pulmonary delivery applications in industries. ${ }^{50-52}$ On the other hand, alginate lyase was found to cleave the $\beta$-glycosidic bonds of bacterial alginate through $\beta$-elimination of glycosidic bonds producing unsaturated oligosaccharides with double bonds at the non-reducing end. ${ }^{53}$ It is worth underling that the co-administration of alginate lyase was proposed as a mean to increase the efficacy of antibiotics in the respiratory tract, even if the mechanism of action and the efficacy of approach are still under investigation. ${ }^{53-57}$

The actual immobilization of enzymes on the particles - surface was preliminarily evaluated by FTIR measurements. As underlined in the Experimental Section, PLLA/PDLA_DCM_0.5_60 particles - were used. Figure S2 and Figure S3 show the spectra of free enzymes, aminolyzed particles and enzyme-- particles. In the spectra of the treated samples, the absorption bands, characteristic of the enzymes, are visible, that is at ca. $1600 \mathrm{~cm}^{-1}$ for the papain based - particles and at ca. $1700 \mathrm{~cm}^{-1}$ for the - particles treated with alginate lyase. As the samples were 
extensively washed, this finding is a preliminary indication of a strong interaction between the polymer and the enzymes.

The effectiveness of the enzyme-- particles systems to catalyze the degradation of some of the mucus components was evaluated by applying the QCM technique. In particular, the effect of papain-based - particles on mucin and that of alginate lyase-based - particles on alginate was considered. In the case of the former system, mucin was adsorbed on the gold coated quartz crystal at $\mathrm{pH} 6.3$ for 30 minutes, leading to a mass density of $150 \pm 5 \mathrm{ng} / \mathrm{cm}^{2}$, which value is in accordance with data found in the literature. ${ }^{58}$ Then, papain- were introduced into the measuring chamber, left in contact with the mucin layer at room temperature and after $30 \mathrm{~min}$ the measuring chamber was flushed with pure water. The mass density of the degraded mucin layer reached a value of $10 \pm 5 \mathrm{ng} / \mathrm{cm}^{2}$-The above relevant decrement, which can be related to the degradation and subsequent solubilization of the mucin layer, demonstrated the degradative ability of the enzyme combined with the polymer - particles.

As relates to the characterization of the degradative action of alginate lyase-particles upon alginate, the QCM measurements were carried out following the above described procedure. In this case, the adsorption of alginate onto the surface of the quartz crystal lead to a mass density of $1150 \pm 10 \mathrm{ng} / \mathrm{cm}^{2}$, while the treatment with alginate lyase-particles led to a decrease of mass density, after the washing steps, of $380 \pm 10 \mathrm{ng} / \mathrm{cm}^{2}$. The mass density decrease was found to be not so relevant as that found for the papain-based system, likely due to the different configuration of the polysaccharidic alginate layer deposited onto the QCM respect to the protein layer, as in the case of mucin, and consequently to the different diffusion of the two enzymes through the respective layers.

In order to corroborate the above findings, catalytic tests were performed with the aim at verifying not only the effectiveness of the enzyme immobilization procedure but also the stability of the enzymes after their immobilization. On this respect, it is worth underling that 
the catalytic activity loss depends on the chemical interactions occurring between enzyme molecules and polymer functional groups. Indeed, it is well known that the covalent immobilization of an enzyme onto the surface of a solid matrix may result in a loss of activity because the active sites might be hidden or the enzyme structure might be affected. ${ }^{59}$

To assess the influence of the conjugation of papain and alginate lyase with -particles, their enzymatic activity was spectrophotometrically evaluated comparing the correspondent free enzyme activity under identical assay conditions. The catalytic tests were performed following the protocols reported in the section S1of Supporting Information. Papain residual catalytic activity was found to be $(96 \pm 3) \%$ with respect to the same amount of free papain, corresponding to a $(38 \pm 3) \%$ of immobilization yield.

For comparison, in a previous work, we immobilized papain onto the surface of poly(styreneco-maleic anhydride) - particles and it was found to retain $79 \pm 11 \%$ of its original activity. ${ }^{51}$ Taking into account other nano-supports, papain immobilized on magnetic gold nanocomposites showed a residual catalytic activity of $(47 \pm 5) \%{ }^{60}$ whereas papain covalently conjugated with poly(acrylic acid) - particles showed a residual catalytic activity of (42.21 \pm $19.54) \%{ }^{50}$ and $(47.8 \pm 0.64) \% .{ }^{61}$ Indeed, the differences in residual catalytic activity can be related to the different chemical interactions between the protein and the support material. As relates to alginate lyase, its residual catalytic activity at $37^{\circ} \mathrm{C}$ was found to be $(89 \pm 6) \%$ with respect to the same amount of free alginate lyase, corresponding to a $(59 \pm 1) \%$ of immobilization yield. Islan et al. $^{62}$ proposed the entrapment of alginate lyase into polysaccharidic microspheres loaded with the antibiotic ciprofloxacin, in order to facilitate its diffusion through the mucus barrier. The residual catalytic activity, after release from the microcapsules, was found to be $76 \%$, under simulated intestinal conditions. For comparison with other supports, alginate lyase immobilized onto cellulose acetate membranes, ${ }^{63}$ retaining 
its full catalytic activity, whereas recombinant His-tagged alginate lyase immobilized onto magnetic - particles retained about $90 \%$ of its original activity. ${ }^{64}$

The high retention of enzyme activity, for the both studied enzymes, indicates the advantages of our immobilization system, which is based on a stable covalent conjugation of the enzyme molecules onto the surface of a biocompatible and biodegradable polymer.

\subsection{Polymer - particles encapsulation}

As described in the Experimental Section, the polymer - particles encapsulation was accomplished by using the preliminary co-precipitation with $\mathrm{CaCO}_{3}$. - The particles loaded$\mathrm{CaCO}_{3}$ microparticles were characterized by means of FTIR and FE-SEM measurements. In Figure $4 \mathrm{~S}$, the spectrum of the neat $\mathrm{CaCO}_{3}$ microparticles is compared with that of a sample co-precipitated with the sc-PLA - particles. It is evident that in the spectrum of the latter system, together with the characteristic peaks of the $\mathrm{CaCO}_{3},{ }^{65}$ a small signal around $1750 \mathrm{~cm}^{-1}$ appears, which can be ascribed to PLA carbonyl stretching. This finding gives a preliminary evidence of the effectiveness of the co-precipitation in giving a $\mathrm{CaCO}_{3} / \mathrm{sc}-\mathrm{PLA}$ - particles composite system. In order to study the morphology of the above system, FE-SEM measurements were carried out. Figure 4 shows the $\mathrm{CaCO}_{3}$ microparticles without (left) and with (right) the loaded particles. 


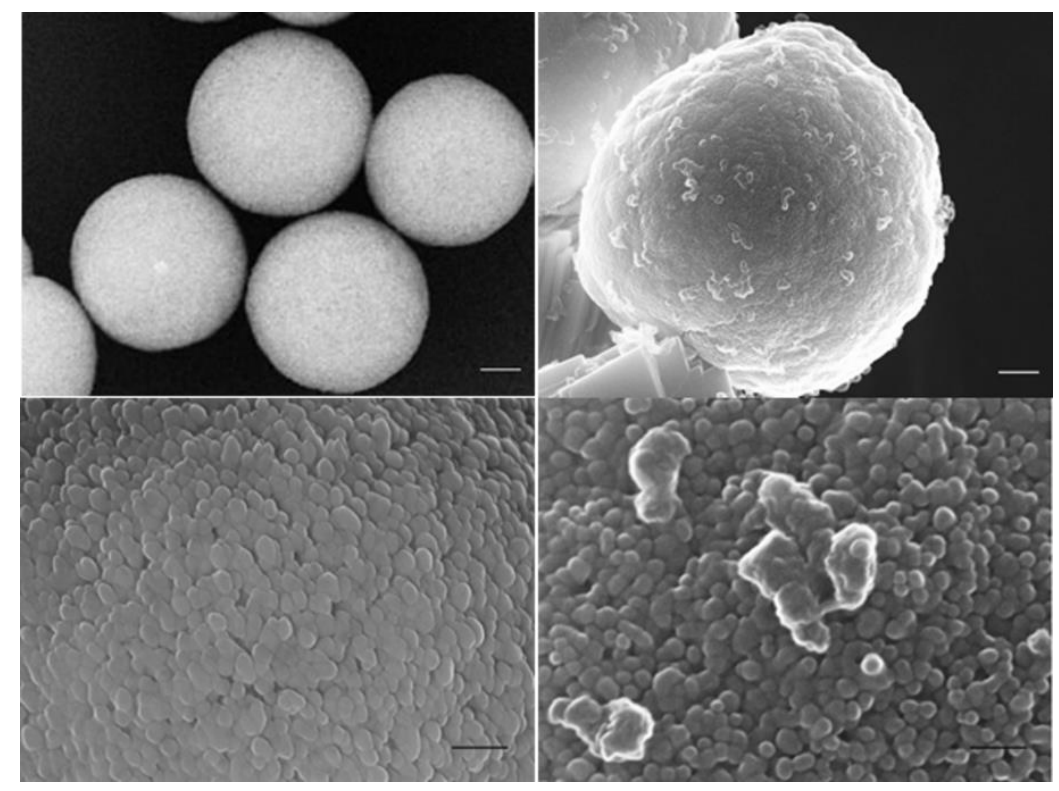

Figure 4. SEM images of $\mathrm{CaCO}_{3}$ microparticles without (left) and with (right) the loaded PLA particles. Top scale bars are $1 \mu \mathrm{m}$, bottom scale bars are $200 \mathrm{~nm}$.

The presence of - particles in the solution turned out to change the dimension of the resulting $\mathrm{CaCO}_{3}$ microparticles, the average dimension passing from $3 \mu \mathrm{m}$ in the case of the neat $\mathrm{CaCO}_{3}$ microparticles to $7 \mu \mathrm{m}$ for the system $\mathrm{CaCO}_{3} / \mathrm{sc}-\mathrm{PLA}$ - particles. Moreover, the presence of a nanometric particulate on the PLA loaded- $\mathrm{CaCO}_{3}$ microparticle surfaces is evident if compared to the microparticles without - particles, which show the characteristic roughness of the simple $\mathrm{CaCO}_{3}$. It is relevant to underline that the particulate size appears approximately around 200 $\mathrm{nm}$, in good agreement with the dimensions evaluated for the free - particles.

The so-fabricated microparticles were then used for template-assisted LbL assembly of three bilayers of oppositely charged DEX and PARG. As reported, the following dissolution of $\mathrm{CaCO}_{3}$ microparticles by EDTA result in the formation of hollow microcapsules. In order to evidence the capability of the enzyme to degrade the shell of the capsules, thus leaving the particles, enfolded inside the capsules, to reach the target system, the morphology of unloaded and free papain loaded microcapsules were investigated by confocal microscopy. As explained 
in the Experimental Section, to this purpose, the shell of the microcapsules was labeled by depositing DEX-FITC as fifth layer. Figure 6 shows the unloaded (left) and free papain loaded (right) microcapsules.
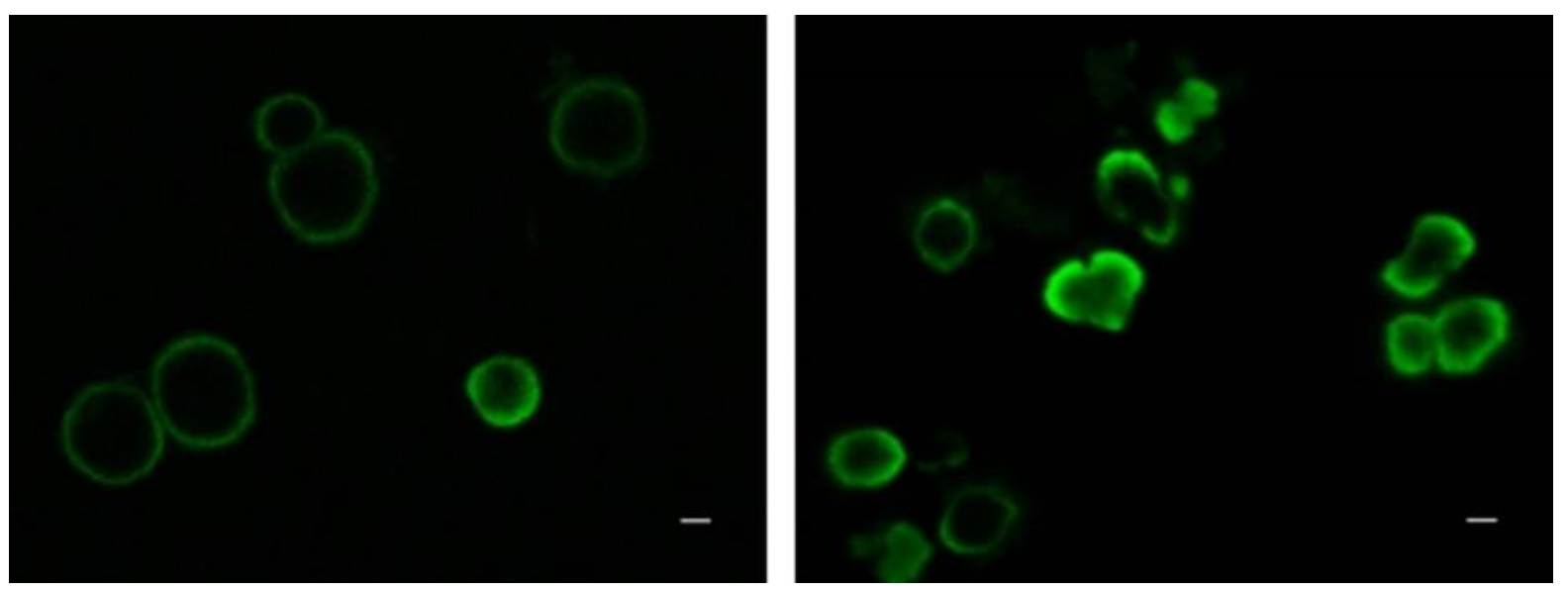

Figure 5. Confocal fluorescence microscopy images of unloaded (left) and free papain loaded (right) microcapsules, labeled by depositing DEX-FITC as fifth layer. Scale bars are $1 \mu \mathrm{m}$.

Figure 5 shows the non-degraded microcapsules (left) and degraded microcapsules (right) after 12 hours of enzyme digestion. The loss of the spherical shape is clearly visible as well as the appearance of large cracks and frayed edges. Similar results were previously observed with poly arginine and poly (L-aspartic) acid microcapsules loaded with a highly active mix of proteases (Pronase®). ${ }^{66}$

Conversely, in this work for the first time to the best of the authors' knowledge, a single protease, namely papain, was demonstrated to be capable of promoting the self-degradation of polymeric microcapsules.

\subsection{Treatment of hydrogels with the prepared enzyme-based systems}

The activity of the enzyme-based formulations was evaluated by determining the loss of viscosity of two hydrogels, differing for the chemical composition and viscosity. The protocol for the preparation of the used hydrogels are reported in the section S2 of Supporting 
Information. The hydrogels were designed by taking into account the specific activity of the chosen enzymes, i.e. papain and alginate lyase, as well as the main constituents of the real mucus. In particular, the application of mucin-based hydrogel allowed to evidence the proteolytic activity of papain, while for that constituted by alginate it was possible to prove the effect of alginate lyase in cleaving the $\beta$-glycosidic bonds of bacterial alginate. It is worth underling that the hydrogel and the solution containing the enzymes were put in contact (at 37 ${ }^{\circ} \mathrm{C}$ for 3.5 hours) without stirring in order to evidence, in a more realistic way, the specific activity of the enzyme-based materials, which may be related also to their diffusion capacity. The hydrogel, based on mucin (hydrogel_mucin) was contacted with free papain (hydrogel_mucin+papain), - particles containing papain (hydrogel_mucin+ papain-- particles) and encapsulated - particles containing papain (hydrogel_mucin+encapsulated papainparticles). In the case of the latter sample, as previously described, free papain was inserted inside the capsules in order to promote their opening in the hydrogel environment. The viscosity of the hydrogel based on alginate (hydrogel_alginate) turned out to have a higher viscosity with respect to hydrogel_mucin, because of its cross-linked structure. The application of the above system allowed to verify also the capability of the - particles to diffuse through the dense hydrogel structure. Similar experiments were carried out with the hydrogel_alginate.

Table 3. Characterization results of the neat hydrogels and of those treated with enzyme-based systems

\begin{tabular}{lc}
\hline Sample code & viscosity \\
& {$[\boldsymbol{c P}]$} \\
\hline hydrogel_mucin & $17.3 \pm 1.6$ \\
hydrogel_mucin + papain & $17.1 \pm 1.6$ \\
hydrogel_mucin + papain-- particles & $14.0 \pm 1.6$
\end{tabular}


hydrogel_mucin + encapsulated papain-- particles

hydrogel_alginate

hydrogel_alginate + alginate lyase

hydrogel_alginate + alginate lyase-- particles

hydrogel_alginate+encapsulated alginate lyase-- particles
$14.9 \pm 1.5$

$15900 \pm 192$

$15000 \pm 110$

$10000 \pm 503$

$12000 \pm 600$

Considering the above data, a different behaviour was found for the samples treated with free enzyme and with - the particles. Indeed, while the enzymes, both papain and alginate lyase, were found not to change significantly the viscosity of the hydrogel, the contact with enzymeparticles led to a relevant decrement. These results demonstrated the capacity of the - particles of penetrating the structure of the hydrogel, which phenomenon allows the enzymes, anchored to the polymer particles, to perform their activity in a more efficient way. Conversely, the enzymes resulted to remain stacked on the surface of the hydrogel, thus limiting their activity on the hydrogel components. It is relevant to underline that the insertion of - particles into the microcapsules was found to decrease the enzyme activity, as the decrement of hydrogel viscosity turned out to be more limited in this case with respect to the systems where the particles, containing enzymes, where directly put in contact with the hydrogel. Nevertheless, as the enzyme maintained a reasonable activity it is possible to infer that the designed system acted properly, both the papain inserted inside the capsule and the enzymes anchored to the particles.

The effect of papain, associated with the polymer - particles, on the viscosity of a mucus modelbased on hydrogel was studied by Muller et al. ${ }^{50}$ for the system constituted of papainpolyacrilic acid - particles. In this case, a decrement of the relative viscosity of ca. $80 \%$ was obtained by using a concentration of enzyme-- particles of $0.2 \% \mathrm{w} / \mathrm{v}$, which value turned out to be much higher than that applied in our system, that is $0.01 \% \mathrm{w} / \mathrm{v}$. Moreover, it is worth 
underling that conversely to our experimental procedure, where the hydrogel was statically put in contact with papain-- particles, in the former work the mucus model was mixed with the enzymes or enzyme-- particles. As previously underlined, the above approach does not mimic the real drug administration and it does not allow to evidence the capability of the enzymebased materials to diffuse into the mucus structure. In the light of these considerations, it is possible to infer that our developed multicomponent systems, composed of enzyme-based particles contained inside degradable microcapsules, represent a promising and alternative material to be applied in different biomedical applications, such as those connected with the overproduction of dense mucus.

\section{Conclusions}

In this work, the effectiveness of novel enzyme-based multicomponent polymer systems was proved. The developed materials combine the proper features of a polymer enzymatic support, that is the nanometric dimension, the biocompatibility and the biodegradability with the high activity of the enzymes covalently linked to the polymer surface. In order to enhance the characteristic of the polymer matrix, particularly in terms of resistance to enzymatic degradation, stereocomplex polylactic acid (PLA), which is formed by the combination of an equimolar mixture of poly(L-lactide) (PLLA) and poly(D-lactide) (PDLA), was used and particles were prepared by applying the simple nanoprecipitation approach. The following polymer functionalization, accomplished by using an aminolysis reaction, allowed to create functional groups, which are necessary to link the enzyme, as well as to tune the particle dimension without significantly changing the surface negative charge, thus making the particles potentially capable of diffusing into the mucus structure. Indeed, in order to render the prepared system applicable to an inhalation administration, such as that used in pathologies characterized by the overproduction of mucus, the particles were encapsulated into polymer 
microcapsules, which were designed to contain also an enzyme capable of promoting their selfdegradation. Conversely to free enzymes, the developed multicomponent systems turned out to significantly diminish the viscosity of two ad hoc prepared hydrogels. Accordingly, the results demonstrated the catalytic activity of the chosen enzymes, namely papain and alginate lyase, towards the degradation of the mucus components as well as the capacity of the - particles to diffuse inside the hydrogel structure. Indeed, the developed materials result to hold promising characteristics not only in terms of performances but also because their preparation is based on commercial materials and on simple and low cost approaches.

\section{References}

(1) Homaei, A. A.; Sariri, R.; Vianello, F.; Stevanato R. Enzyme Immobilization: an Update. J. Chem. Biol. 2013, 6, 185-205, DOI: 10.1007/s12154-013-0102-9.

(2) Tran, D. N.; Balkus, Jr. K. J. Perspective of Recent Progress in Immobilization of Enzymes. ACS Catal. 2011, 1, 956-968, DOI: 10.1021/cs200124a.

(3) Cipolatti, E. P.; Silva, M. J. A.; Klein, M.; Feddern, V.; Feltes, M. M. C.; Oliveira, J. V.; Ninow, J. L.; de Oliveira, D. Current Status and Trends in Enzymatic Nanoimmobilization. J. Mol. Catal. B: Enzym. 2014, 99, 56- 67, DOI: 10.1016/j.molcatb.2013.10.019.

(4) Ansari, S. A.; Husain Q. Potential Applications of Enzymes Immobilized on/in Nano Materials: a Review. Biotechnol. Adv. 2012, 30, 512-523, DOI:10.1016/j.biotechadv.2011.09.005.

(5) Mahmoud, K. A.; Male, K. B.; Hrapovic, S.; Luong J. H. T. Cellulose Nanocrystal/Gold Nanoparticle Composite as a Matrix for Enzyme Immobilization. ACS Appl. Mater. Interfaces 2009, 1, 1383-1386. DOI: 10.1021/am900331d. 
(6) Kim, M. I.; Hama, H. O.; Oh, S.-D.; Park, H. G.; Chang, H. N.; Choi, S.-H. Immobilization of Mucor Javanicus Lipase on Effectively Functionalized Silica Nanoparticles. J. Mol. Catal. B: Enzym. 2006, 39, 62-68, DOI: 10.1016/j.molcatb.2006.01.028.

(7) Koneracka, M.; Kopcansky, P.; Timko M.; Ramchand C. N. Direct Binding Procedure of Proteins and Enzymes to Fine Magnetic Particles. J. Magn. Magn. Mater. 2002, 252, 409-411, DOI: 10.1016/s0304-8853(02)00595-4.

(8) Konwarh, R.; Karak, N.; Rai, S. K.; Mukherjee, A. K. Polymer-assisted Iron Oxide Magnetic Nanoparticle Immobilized Keratinase. Nanotechnology 2009, 20, 225-35, DOI: $10.1088 / 0957-4484 / 20 / 22 / 225107$.

(9) Kaziem, A. E.; Gao, Y.; He, S.; Li J. Synthesis and Insecticidal Activity of EnzymeTriggered Functionalized Hollow Mesoporous Silica for Controlled Release. J. Agric. Food Chem. 2017, 65, 7854-7864, DOI: 10.1021/acs.jafc.7b02560.

(10) Xing, Q.; Eadula, S. R.; Lvov. Y. M. Cellulose Fiber-Enzyme Composites Fabricated through Layer-by-Layer Nanoassembly. Biomacromolecules 2007, 8, 19871991, DOI: 10.1021/bm070125x.

(11) Flores-Maltos, A.; Rodríguez-Durán, L. V.; Renovato, J.; Contreras, J. C.; Rodríguez, R.; Aguilar, C. N. Catalytical Properties of Free and Immobilized Aspergillus Niger Tannase. Enzyme Res. 2011, ID 768183, DOI: $10.4061 / 2011 / 768183$.

(12) Chang, M. Y.; Juang, R. S. Use of Chitosan-Clay Composite as Immobilization Support for Improved Activity and Stability of $\square$-glucosidase. Biochem. Eng. J. 2007, 35, 93-98, DOI: 10.1016/j.bej.2007.01.003.

Chern, J. T.; Chao, Y. P. Chitin-Binding Domain Based Immobilization of DHydantoinase. J. Biotechnol. 2005, 117, 267-275, DOI: 10.1016/j.jbiotec.2005.02.001. 
Production from Bacillus Subtilis via Immobilization Process onto Radiation Synthesized Starch/Dimethylaminoethyl Methacrylate Hydrogel. Carbohydr. Polym. 2011, 87, 1369-1374, DOI: 10.1016/j.carbpol.2011.09.029.

Cunha, A.G.; Fernández-Lorente, G.; Bevilaqua, J. V.; Destain, J.; Paiva, L. M.; Freire, D. M.; Fernández-Lafuente, R.; Guisán, J. M. Immobilization of Yarrowia Lipolytica Lipase-a Comparison of Stability of Physical Adsorption and Covalent Attachment Techniques. Appl. Biochem. Biotechnol. 2008, 146, 49-56, DOI: 10.1007/s12010-007-8073-3.

(16) Gómez, L.; Ramírez, H. L.; Neira-Carrillo, A. Villalonga, R. Polyelectrolyte Complex Formation Mediated Immobilization of Chitosan-Invertase Neoglycoconjugate on Pectin-Coated Chitin. Bioproc. Biosyst. Eng. 2006, 28, 387395, DOI: 10.1007/s00449-005-0043-y.

Datta, S.; Christena, L. R.; Rajaram, Y. R. S. Enzyme Immobilization: an Overview on Techniques and Support Materials. 3 Biotech. 2013, 3, 1-9, DOI $10.1007 / \mathrm{s} 13205-012-0071-7$.

(18) Tyler, B.; Gullotti, D.; Mangraviti, A.; Utsuki, T.; Brem H. Polylactic Acid (PLA) Controlled Delivery Carriers for Biomedical Applications. Adv. Drug Delivery Rev. 2016, 107, 163-175, DOI: 10.1016/j.addr.2016.06.018.

Gardella, L.; Colonna, S.; Fina, A.; Monticelli, O. A Novel Electrostimulated Drug Delivery System Based on PLLA Composites Exploiting the Multiple Functions of Graphite Nanoplatelets. ACS Appl. Mater. Interfaces 2016, 8, 24909-24917, DOI: 10.1021/acsami.6b08808. 
Degradation, and Applications. Macromol. Biosci. 2005, 5, 569-597, DOI: 10.1002/mabi.200500062.

(21) Monticelli, O.; Putti, M.; Gardella, L.; Cavallo, D.; Basso, A.; Prato, M.; Nitti,

S. New Stereocomplex PLA-Based Fibers: Effect of POSS on Polymer Functionalization and Properties. Macromolecules 2014, 47, 4718-4727, DOI: 10.1021/ma500528a.

Brzezínski, M.; Biela, T. Micro-and Nanostructures of Polylactide

Stereocomplexes and their Biomedical Applications. Polym. Int. 2015, 64, 1667-1675, DOI: $10.1002 /$ pi.4961.

Zhu, Y.; Mao, Z.; Gao, C. Aminolysis-based Surface Modification of Polyesters

for Biomedical Applications. RSC Adv. 2013, 3, 2509-2519, DOI: $10.1039 / \mathrm{c} 2 \mathrm{ra} 22358 \mathrm{a}$.

(24) Kim, T. G.; Park, T. G. Biodegradable Polymer Nanocylinders Fabricated by Transverse Fragmentation of Electrospun Nanofibers through Aminolysis. Macromol. Rapid Commun. 2008, 29, 1231-1236, DOI: 10.1002/marc.200800094.

Croll, T. I.; O’Connor, A. J.; Stevens, G. W.; Cooper-White, J. J. Controllable Surface Modification of Poly(lactic-co-glycolic acid) (PLGA) by Hydrolysis or Aminolysis I: Physical, Chemical, and Theoretical Aspects. Biomacromolecules 2004, 5, 463-473, DOI: 10.1021/bm0343040.

(26) Dellacasa, E.; Forouharshad, M.; Rolandi, R.; Pastorino, L; Monticelli, O. Poly(styrene- co -maleic anhydride) Nanoparticles as Protein Carriers. Mater. Lett. 2018, 220, 241-244, DOI:10.1016/j.matlet.2018.03.044. 
Microparticles for Drug Delivery. Glob. Cardiol. Sci. Pract. 2015, 1, 2, DOI:10.5339/gcsp.2015.2.

De Geest, B. G.; De Koker, S.; Sukhorukov, G. B.; Kreft, O.; Parak, W. J.;

Skirtach, A. G.; Demeester, J.; De Smedt, S. C.; Hennink, W. E. Polyelectrolyte Microcapsules for Biomedical Applications. Soft Matter 2009, 5, 282-291, DOI:10.1039/b808262f.

Biotechnology. Trends Biotechnol. 2007, 25, 93-98, DOI:10.1016/j.tibtech.2006.12.007.

(30) Pastorino, L.; Erokhina, S.; Erokhin, V. Smart Nanoengineered Polymeric Capsules as Ideal Pharmaceutical Carriers. Curr. Org. Chem. 2013, 17, 58-64, DOI:10.2174/138527213805289088.

Sukhorukov, G. B.; Donath, E.; Lichtenfeld, H.; Knippel, E.; Knippel, M.;

Budde, A.; Möhwald, H. Layer-by-Layer Self Assembly of Polyelectrolytes on Colloidal Particles. Colloids Surf., A 1998, 137, 253-266, DOI:10.1016/s09277757(98)00213-1.

Hollow Polymer Shells by Colloid-Templated Assembly of Polyelectrolytes. Angew.

Chem., Int. Ed. 1998, 37, 2201-2205, DOI:10.1002/(SICI)15213773(19980904)37:16<2201::AID-ANIE2201>3.0.CO;2-E.

Sukhorukov, G. B.; Donath, E.;Davis, S.; Lichtenfeld, H.; Caruso, F.; Popov, V. I.; Möhwald, H. Stepwise Polyelectrolyte Assembly on Particle Surfaces: a Novel Approach to Colloid Design. Polym. Adv. Technol. 1998, 9, 759-767, DOI:10.1002/(SICI)1099-1581(1998100)9:10/11<759::AID-PAT846>3.0.CO;2-Q. 
Coprecipitation: A Tool for Protein Encapsulation. Biotechnol. Prog. 2008, 21, 918 925, DOI:10.1021/bp0495825.

Lauth, V.; Maas, M.; Rezwan, K. Coacervate-Directed Synthesis of CaCO3 Microcarriers for pH-Responsive Delivery of Biomolecules. J. Mater. Chem. B 2014, 2, 7725-7731, DOI:10.1039/c4tb01213e.

Sukhorukov, G. B.; Volodkin, D. V.; Günther, A. M.; Petrov, A. I.; Shenoy, D.

B.; Möhwald, H. Porous Calcium Carbonate Microparticles as Templates for Encapsulation of Bioactive Compounds. J. Mater. Chem. 2004, 14, 2073-2081, DOI:10.1039/b402617a.

Patel, N.; Davies, M. C.; Hartshorne, M.; Heaton, R. J.; Roberts, C. J.; Tendler, S. J. B.; Williams, P. M. Immobilization of Protein Molecules onto Homogeneous and Mixed Carboxylate-Terminated Self-Assembled Monolayers. Langmuir 1997, 13, 6485-6490, DOI:10.1021/la970933h.

Volodkin, D. V.; Petrov, A. I.; Prevot, M.; Sukhorukov, G. B. Matrix

Polyelectrolyte Microcapsules: New System for Macromolecule Encapsulation. Langmuir 2004, 20, 3398-3406, DOI:10.1021/1a036177z.

Volodkin, D. CaCO3 Templated Micro-Beads and -Capsules for

Bioapplications. Adv. Colloid Interface Sci. 2014, 207, 306-324, DOI:10.1016/j.cis.2014.04.001.

(40) Voinova, M. V.; Rodahl, M.; Jonson, M.; Kasemo, B. Viscoelastic Acoustic Response of Layered Polymer Films at Fluid-Solid Interfaces: Continuum Mechanics Approach. Phys. Scr. 1999, 59, 391-396, DOI:10.1238/physica.regular.059a00391. 
Polymer Films and Complex Biomolecular Systems at the Solution-Surface Interface. Biomacromolecules 2003, 4, 1099-1120, DOI:10.1021/bm020116i.

$$
\text { Kujawa, P.; Schmauch, G.; Viitala, T.; Badia, A.; Winnik, F. M. Construction }
$$
of Viscoelastic Biocompatible Films via the Layer-by-Layer Assembly of Hyaluronan and Phosphorylcholine-Modified Chitosan. Biomacromolecules 2007, 8, 3169-3176, DOI:10.1021/bm7006339.

Viitala, T.; Hautala, J. T.; Vuorinen, J.; Wiedmer, S. K. Structure of Anionic Phospholipid Coatings on Silica by Dissipative Quartz Crystal Microbalance. Langmuir 2007, 23, 609-618, DOI:10.1021/1a060923t.

(44) Rao, J. P.; Geckeler K. E. Polymer Nanoparticles: Preparation Techniques and Size-Control Parameters. Prog. Polym. Sci. 2011, 36, 887-913, DOI:10.1016/j.progpolymsci.2011.01.001. Soppimath, K. S.; Aminabhavi, T. M.; Kulkarni, A. R.; Rudzinski W. E. Biodegradable Polymeric Nanoparticles as Drug Delivery Devices. J. Controlled Release 2001, 70, 1-20, DOI:10.1016/s0168-3659(00)00339-4.

(46) Eleuteri, M.; Pastorino, L.; Monticelli, O. On the Degradation Properties of Electrospun Fibers Based on PLLA: the Effect of a Drug Model Modification. Polym. Degrad. Stab. 2018, 153, 109-117, DOI 10.1016/j.polymdegradstab.2018.04.013.

$$
\text { Liu, Y.; Chen, X.; Wang, L.; Yang, T.; Yuan, Q.; Ma G. Surface Charge of PLA }
$$
Microparticles in Regulation of Antigen Loading, Macrophage Phagocytosis and Activation, and Immune Effects in Vitro. Particuology 2014, 17, 74-80, DOI:10.1016/j.partic.2014.02.006. 
Nanoparticle Transport. Macromol. Biosci. 2010, 10, 1473-1483, DOI:10.1002/mabi.201000137.

(49) Nampoothiri, K. M.; Nair, N. R.; Pappy John, R. An Overview of the Recent Developments in Polylactide (PLA) Research, Bioresource Technol. 2010, 101, 84938501. DOI: 10.1016/j.biortech.2010.05.092.

(50) Müller, C.; Leithner, K.; Hauptstein, S.; Hintzen, F.; Salvenmoser, W.; Bernkop-Schnürch, A. Preparation and Characterization of Mucus-Penetrating Papain/Poly(acrylic acid) Nanoparticles for Oral Drug Delivery Applications. $J$. Nanopart. Res. 2012, 15, DOI:10.1007/s11051-012-1353-z. Müller, C.; Perera, G.; König, V.; Bernkop-Schnürch, A. Development and In Vivo Evaluation of Papain-Functionalized Nanoparticles. Eur. J. Pharm. Biopharm. 2014, 87, 125-131, DOI:10.1016/j.ejpb.2013.12.012. Dünnhaupt, S.; Kammona, O.; Waldner, C.; Kiparissides, C.; BernkopSchnürch, A. Nano-Carrier Systems: Strategies to Overcome the Mucus Gel Barrier. Eur. J. Pharm. Biopharm. 2015, 96, 447-453, DOI:10.1016/j.ejpb.2015.01.022. Alves, D.; Sileika, T.; Messersmith, P. B.; Pereira, M. O. PolydopamineMediated Immobilization of Alginate Lyase to Prevent P. Aeruginosa Adhesion. Macromol. Biosci. 2016, 16, 1301-1310, DOI:10.1002/mabi.201600077. Alkawash, M. A.; Soothill, J. S.; Schiller, N. L. Alginate Lyase Enhances Antibiotic Killing of Mucoid Pseudomonas Aeruginosa in Biofilms. APMIS 2006, 114, 131-138, DOI:10.1111/j.1600-0463.2006.apm_356.x. Bjarnsholt, T.; Ciofu, O.; Molin, S.; Givskov, M.; Høiby, N. Applying Insights from Biofilm Biology to Drug Development — Can a New Approach be Developed? Nat. Rev. Drug Discovery 2013, 12, 791-808, DOI:10.1038/nrd4000. 
on the Gentamicin Resistance of Pseudomonas Aeruginosa in Mucoid Biofilms. $J$. Appl. Microbiol. 2016, 121, 126-135, DOI:10.1111/jam.13153.

Antimicrobial Enzymes: An Emerging Strategy to Fight Microbes and Microbial Biofilms. Biotechnol. J. 2013, 8, 97-109, DOI:10.1002/biot.201200313.

$$
\text { Oh, S.; Wilcox, M.; Pearson, J. P.; Borrós, S. Optimal Design for Studying }
$$

Mucoadhesive Polymers Interaction with Gastric Mucin Using a Quartz Crystal Microbalance with Dissipation (QCM-D): Comparison of Two Different Mucin Origins. Eur. J. Pharm. Biopharm. 2015, 96, 477-483, DOI:10.1016/j.ejpb.2015.08.002.

(59) Garcia-Galan, C.; Berenguer-Murcia, Á.; Fernandez-Lafuente, R.; Rodrigues,

R. C. Potential of Different Enzyme Immobilization Strategies to Improve Enzyme Performance. Adv. Synth. Catal. 2011, 353, 2885-2904, DOI:10.1002/adsc.201100534.

$$
\text { Sahoo, B.; Sahu, S. K.; Bhattacharya, D.; Dhara, D.; Pramanik, P. A Novel }
$$
Approach for Efficient Immobilization and Stabilization of Papain on Magnetic Gold Nanocomposites. Colloids Surf., $\quad$ B 2013, 101, 280-289, DOI:10.1016/j.colsurfb.2012.07.003.

$$
\text { Köllner, S.; Dünnhaupt, S.; Waldner, C.; Hauptstein, S.; Pereira de Sousa, I.; }
$$

Bernkop-Schnürch, A. Mucus Permeating Thiomer Nanoparticles. Eur. J. Pharm. Biopharm. 2015, 97, 265-272, DOI:10.1016/j.ejpb.2015.01.004.

(62) Islan, G. A.; Bosio, V. E.; Castro, G. R. Alginate Lyase and Ciprofloxacin CoImmobilization on Biopolymeric Microspheres for Cystic Fibrosis Treatment. Macromol. Biosci. 2013, 13, 1238-1248, DOI:10.1002/mabi.201300134. 
Meshram, P.; Dave, R.; Joshi, H.; Dharani, G.; Kirubagaran, R.; Venugopalan, V. P. A Fence that Eats the Weed: Alginate Lyase Immobilization on Ultrafiltration Membrane for Fouling Mitigation and Flux Recovery. Chemosphere 2016, 165, 144 151, DOI:10.1016/j.chemosphere.2016.09.017.

(64) Shin, J. W.; Choi, S. H.; Kim, D. E.; Kim, H. S.; Lee, J.-H.; Lee, I. S.; Lee, E. Y. Heterologous Expression of an Alginate Lyase from Streptomyces sp. ALG-5 in Escherichia coli and its Use for Preparation of the Magnetic Nanoparticle-Immobilized Enzymes. Bioprocess Biosyst. Eng. 2010, 34, 113-119, DOI:10.1007/s00449-0100452-4.

(65) Vagenas, N. Quantitative Analysis of Synthetic Calcium Carbonate Polymorphs Using FT-IR Spectroscopy. Talanta 2003, 59, 831-836, DOI:10.1016/s00399140(02)00638-0.

(66) Borodina, T.; Markvicheva, E.; Kunizhev, S.; Möhwald, H.; Sukhorukov, G.

B.; Kreft, O. Controlled Release of DNA from Self-Degrading Microcapsules. Macromol. Rapid Commun. 2007, 28, 1894-1899, DOI:10.1002/marc.200700409. 